\title{
Implementing Technological Change at Schools: The Impact of Online Communication with Families on Teacher Interactions through Learning Management System
}

\author{
Ina Blau \\ Open University of Israel, \\ Raanana, Israel; \\ Western Galilee College, Akko, \\ Israel \\ ina.blau@gmail.com
}

\author{
Mira Hameiri \\ Oranim Academic College of \\ Education, Tiv'on, Israel
}

\begin{abstract}
The integration of a Learning Management System (LMS) in K-12 opens new possibilities for online interaction among teachers, students, and parents. This paper examines the implementation of an LMS called Mashov (meaning "feedback" in Hebrew, as well as the acronym of "Immediacy, Transparency, and Supervision") in ten Israeli secondary schools during the years 20072009. Consistent with the Diffusion of Innovation Theory (Rogers, 2003), a log analysis showed a significant increase of interactions among school staff, measured as (1) the number of logins into the system, (2) the percentage of data concerning lesson topics and events entered by teachers into the system, and (3) the number of messages sent to colleagues through the system during each year. Consistent with the approach of implementing changes at schools by expanding circles of interaction and taking into consideration all stakeholders (Fuchs, 1995), schools that used the Mashov family application, which allows teacher-student and teacher-parent online interactions, significantly enhanced the amount of interactivity among teachers, compared to schools that used the system for staff interactions only. The findings suggest that students and parents are important stakeholders, whose active involvement increases exchange of pedagogical information and promote interaction among teachers. Therefore, including families in implementing technological change plays an important role in the successful adoption of new technologies at schools.
\end{abstract}

Keywords: online interactivity, LMS - Learning Management System, technology implementation at schools, Mashov staff and family applications

Material published as part of this publication, either on-line or in print, is copyrighted by the Informing Science Institute. Permission to make digital or paper copy of part or all of these works for personal or classroom use is granted without fee provided that the copies are not made or distributed for profit or commercial advantage AND that copies 1) bear this notice in full and 2) give the full citation on the first page. It is permissible to abstract these works so long as credit is given. To copy in all other cases or to republish or to post on a server or to redistribute to lists requires specific permission and payment of a fee. Contact Publisher@InformingScience.org to request redistribution permission.

\section{Introduction}

If you cannot measure something in your organization, you cannot manage it (Drucker, 2007). The main objectives of online Learning Management Systems (LMS) in organizations are to simplify the administration of learning programs and support communication among colleagues (Nichani, 2001). An effective

\section{Editor: Alex Koohang}

An earlier, shorter version of this paper was presented at the Chais conference 2010, in Raanana, Israel, and included in Y. Eshet-Alkalai, A. Caspi, S. Eden, N. Geri, \& Y. Yair (Eds.), Proceedings of the Chais conference on instructional technologies research 2010: Learning in the technological era. Raanana: The Open University of Israel. http://www.openu.ac.il/research center eng/conferences.html 
LMS helps to target, deliver, track, analyze, and report the learning "condition" within the organization (Rengarajan, 2001). Recently LMS became a necessary management tool in K-12 education. School principals and educational administrators often need to decide which system will best suit their specific needs and open channels for communication among the staff (Cameron \& Mahoney, 2008). Some researchers have exploited the potential of LMS, many of which automatically keep logs of user activity, both for research and the design of practical online learning applications (Black, Dawson, \& Priem, 2008). The present study continues this work, seeking to explore whether the interactivity among teachers can be measured via logs of their activities within LMS. The introduction section is divided into three parts: the first one discusses online educational systems that help to manage learners versus systems that focuses on content provided to the learner; the second section presents the theoretical frameworks of this study and defines interactivity - the variable measured in this research; the last section describes the Mashov LMS studied in this research and presents its two application: for staff and for families - students and their parents.

Some authors use the term LMS for systems that include different content components (Chen \& Epperson, 2008). However, such terminology usage neutralizes the distinction between LMS and so called Content Management Systems - CMS (Tsai \& Ernst, 2009) or Learning Content Management Systems - LCMS. This paper follows the distinction made by Greenberg (2002), according to which the primary objective of LMS in educational settings is to manage learners, i.e., to keep track of their progress and performance across different types of learning activities. In contrast, CMS or LCMS manage the content provided to the learner (for detailed discussion about differences between LMS and LCSM see also: Maleh, Lee, Ho, \& Chong, 2004).

By providing data concerning teacher activities, an LMS opens possibilities to monitor and evaluate the process of change in educational institutions, as well as to plan, make decisions, and design future policies (Heathcote \& Dawson, 2005). But the adoption of educational technology is a complex issue; even if teachers are proficient in using technologies, this does not mean that they believe it is a valuable tool when used in educational settings (Steel, 2009).

Technological innovations are accepted by people at different rates. Diffusion of Innovation Theory (Rogers, 2003) defined five types of technology adopters: innovators, early adopters, early majority, late majority, and laggards. The distribution of these types follows standard deviations in a bell curve. The innovators $(2.5 \%)$ are eager to adopt innovations and technology is a central interest in their life. The early adopters (13.5\%) understand and appreciate the benefits of a new technology and relate potential benefits to their own needs. The early majority (34\%) is driven by a sense of practicality and wants to be sure that the new technology is stable. The late majority (34\%) prefers to wait until the new technology has become an established standard and receives significant support. Finally, the laggards (16\%) are resistant to new technologies and will use it only as a part of other products.

In educational settings Dori, Tal, and Peled (2002) classified four categories of teachers in a process of technology adoption: (1) "the initiator and path-finder" - the enthusiastic, confident teacher, willing to implement online technologies, (2) "the follower" - the conformist teacher, applying online technologies at convenience, (3) "the avoider" - teacher using technologies when he or she is forced to, and (4) "the antagonist" that will not use technologies in school under any circumstances. Shamir-Inbal, Dayan, \& Kali (2009) pointed to the fact that Dori et al.'s classification, grounded in educational field, seems to align with the types from the more generic Diffusion of Innovation Theory (Rogers, 2003): The initiating teachers (type 1) mapping to innovators and early adopters, followers (type 2) to early majority, avoiders (type 3 ) to late majority, and antagonists (type 4) to laggards. 
Another perspective in understanding how to fulfill the potential of technology in education is to examine the nature of the change process for the school as a whole. Fuchs (1995) suggested a theoretical framework for the classification and evaluation of the change process in educational institutions. Successful implementation of a change is influenced by the individuals involved in the process, stakeholders, and the whole school culture. According to Fuchs, for a change process to be substantial, it has to include, among other factors, interactions between circles of various stakeholders - not only interaction within the internal circle of educational institution (i.e., between school principals and staff), but also interactions with students and their parents.

The use of LMS in schools is not limited to a strictly determined educational role mostly emphasized in the research literature; some systems also function as a new way for online communication and interaction (Blau \& Hameirie, 2010; Georgouli, Skalkidis, \& Guerreiro, 2008). Definitions of interactivity in literature vary in focus (on medium features versus users) and temporal orientation (interactivity as a quality versus interactivity as a process). This research adopted the definition of interactivity as "a process-related variable concerning responsiveness" (Rafaeli \& Ariel, 2007, p. 84). This definition refers to human responsiveness and exchanging different types of information transmitted between communicators. Research showed that interactivity through two-way symmetrical interactive applications provides an opportunity for organizations to build and maintain relationships with their target audiences (Samsup \& Yungwok, 2003) and leads to favorable attitudes and positive evaluation of target audiences towards the organizations (Cho \& Leckenby, 1999; Sundar \& Kim, 2004).

This paper examines the implementation of a LMS called Mashov (meaning "feedback" in Hebrew, as well as the acronym of "Immediacy, Transparency, and Supervision"). (Mashov website is http://www.mashov.info/ [in Hebrew].) This technology is currently adopted in more than 400 Israeli schools. The system includes two applications: the Mashov staff application enables secure online exchange of pedagogical information and communication between teachers, as well as online interactions with students and their parents; the Mashov family application opens access to student data - for the student and his or her parents - and offers the possibility for a two-way communication channel with the school staff. Each member of the organization receives access to the pedagogical information according to his or her position: school principals have access to all the information concerning their institution; heads of departments can see all the information concerning their departments; teachers have access to the information regarding the function of their students, including during the lessons of other teachers; students can access their own information entered by different teachers; parents have access to the information concerning their children's learning and behavior. Online interactions in the Mashov LMS are conducted in two main modes: (1) entering daily data by teachers regarding their lessons, such as lesson topics, educational materials, homework, as well as information about their students, such as attendance, discipline, homework preparation, grades, and (2) direct two-way interactions among teachers, students, and parents through the system.

\section{Research Goals and Hypotheses}

The purpose of this study was to examine different forms of online interactions among educators during the implementation of a new technology in organizations. Specifically the study explored online interactions as (a) logging into the system, (b) reporting data by teachers in a daily basis, and (c) sending messages to colleagues during the three years of implementing the Mashov LMS in 10 Israeli large secondary schools. In addition, the study compared these three measures of online interactions between teachers in schools that implemented the Mashov applications for both staff and families - students and their parents - versus teachers in schools that implemented the LMS for staff only. 
The research hypotheses were:

(1) Based on the Diffusion of Innovation Theory (Rogers, 2003), it was hypothesized that the implementation time would positively influence all three measures of the interactivity (i.e., logging into the system, reporting data on a daily basis, and sending messages to colleagues);

(2) Based on the approach of implementing changes at schools by expanding circles of interaction (Fuchs, 1995), it was hypothesized that opening the possibility for online interactions with students and their parents would augment all three measures of the interactivity among teachers themselves.

\section{Method}

\section{Participants}

The study participants were 1,119 teachers working in 10 Israeli secondary schools (grade 7-12). The schools belong to the same geographical region, were under the same type of governmental supervision, and were similar in terms of ethnic origin, organizational structure, and educational values. The participants started to use the Mashov LMS in September 2006 and to the date of the analysis continuously used the system during three academic years. All the schools were large, including at least 80 staff members. Figure 1 presents the age distribution of the participants whose age was available through the system.

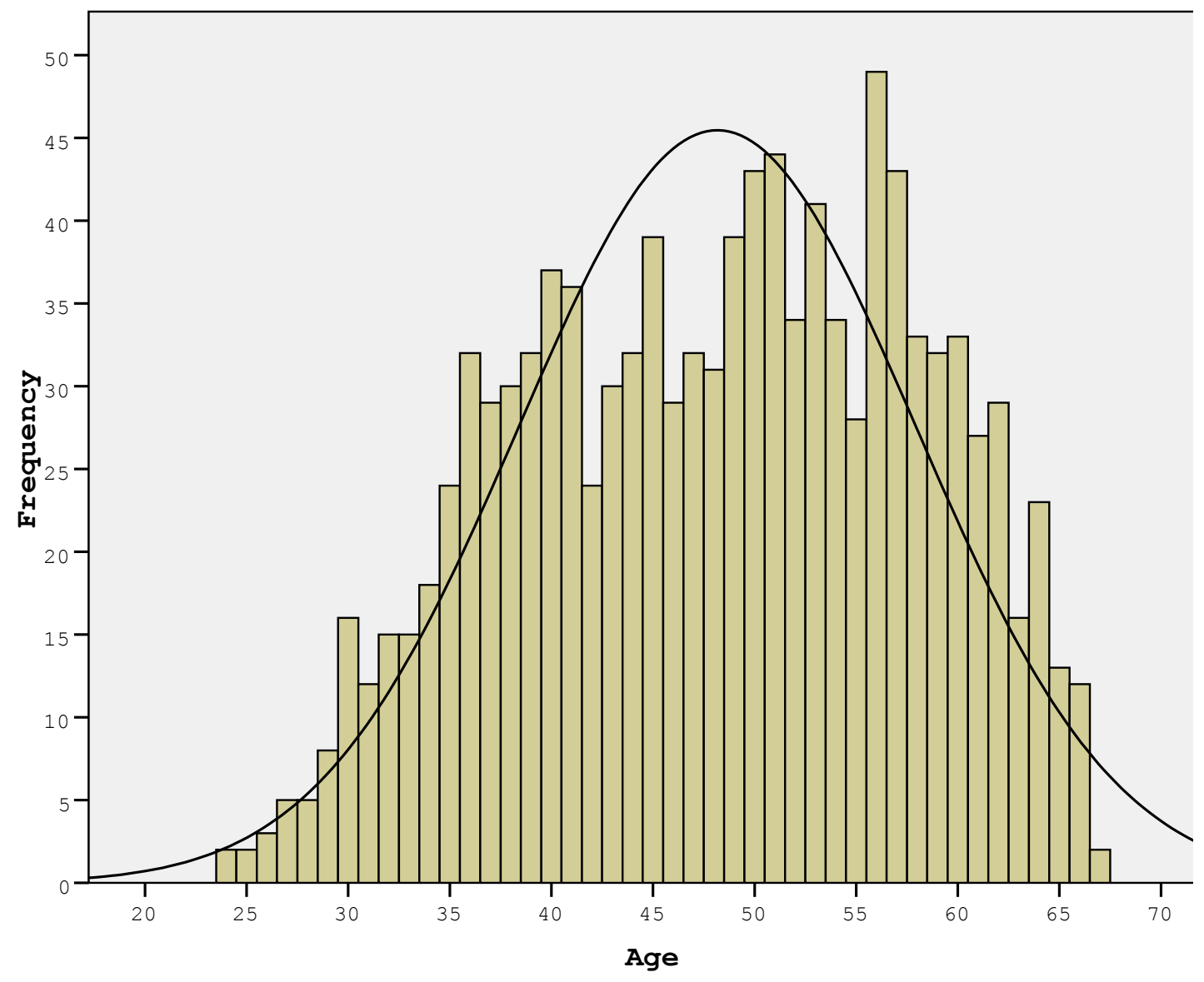

Figure 1: Participant age distribution $(n=1113)$ 
Three of the schools investigated in this research used the Mashov staff LMS, while the other 7 schools used, in addition, the Mashov family application for students and their parents. Table 1 presents the descriptive statistics for teacher age, separately for the teachers in schools that used the Mashov family application and for the teachers in schools that used the staff application only. Teachers in schools without the family application were on average younger than teachers in schools that did not use it $(p<.001)$ and the effect size was medium (Cohen's $d=0.29$ ).

Table 1: Descriptive statistics for the participant age in schools with and without the Mashov family application

\begin{tabular}{lccccccc}
\hline $\begin{array}{l}\text { Use of the Mashov } \\
\text { applications }\end{array}$ & $N$ & Mean & $S D$ & Median & Min & Max & Skewness \\
\hline $\begin{array}{l}\text { Staff and family appli- } \\
\text { cations }\end{array}$ & 828 & 48.89 & 9.66 & 50 & 24 & 67 & -.243 \\
$\begin{array}{l}\text { Staff application only } \\
\text { Total }\end{array}$ & 285 & 46.07 & 9.80 & 46 & 25 & 67 & .001 \\
\hline
\end{tabular}

\section{Instruments}

The analysis was conducted in this study at the level of the individual teacher (and not on a school level). The unit of analysis was the summary of activities in LMS for an academic year for each teacher. The research measured three forms of teacher online activities: (1) the number of teacher logs into the system, (2) the percentage of daily data entered by teachers into the system (e.g., the number of lesson entered - topics, student attendance, behavior events, homework preparation -divided by the number of teacher's total lessons per week), and (3) the number of messages sent by teachers to their colleagues through the system.

\section{Procedure}

A log analysis of all teacher activities during the period of three academic years (from September 2006 until August 2009) was conducted. Only teachers who worked continuously during all the three years were included in the analysis; new staff members, retired teachers, and the teachers having a sabbatical during the period of investigation were excluded from the study. The data was extracted, stored, and analyzed in an anonymous way, which did not enable recognition of teachers or schools.

\section{Results}

The following section includes three parts. Each part provides the answer to both research questions for one measure of interactions between the teachers through the Mashov LMS. First, the results regarding the number of teacher logs into the system will be presented. Following that, the results concerning percentage of the daily data entered by teachers into the system will be reported. We will conclude this section by presenting the data regarding the number of messages sent by teachers to their colleagues through the system.

\section{Interactivity as the Number of Teacher Logs into the System}

In order to test the study hypotheses, series of ANOVA Repeated Measures tests were conducted. Regarding the first research hypothesis, the ANOVA Repeated Measures showed statistically significant main effect of implementation time on the number of teacher logs into the system, $F(2,799)=126.62, p<.001, \eta^{2}=.24$. Post-hoc tests showed significant increase in average 
Implementing Technological Change at Schools

number of teacher logs into the system during all three years of investigation $(187.59,253.40$, and 302.55 logs in average, $p$ 's $<.001)$.

Concerning the second research hypothesis, Table 2 shows average and standard errors for the number of teacher logs into the system - separately for teachers in schools that used both the staff and the family applications versus teachers in schools that implemented the staff application only.

Table 2: The number of teacher logs into the system for schools with and without the Mashov family application

\begin{tabular}{lcc}
\hline $\begin{array}{l}\text { Number of teacher logs } \\
\text { into the system during: }\end{array}$ & $\begin{array}{c}\text { Teachers implementing staff } \\
\text { and family applications } \\
(\boldsymbol{n}=\mathbf{6 6 0}): \text { Means }(\boldsymbol{S E})\end{array}$ & $\begin{array}{c}\text { Teachers implementing } \\
\text { staff application only } \\
(\boldsymbol{n}=\mathbf{1 4 1}): \text { Means }(\boldsymbol{S E})\end{array}$ \\
\hline First year & $212.15(6.18)$ & $72.62(3.38)$ \\
Second year & $277.10(5.33)$ & $142.47(6.01)$ \\
Third year & $336.72(5.10)$ & $142.60(5.87)$ \\
\hline
\end{tabular}

As can be seen from the data presented, teachers who interacted online with students and their parents logged more into the system compared to teachers in schools that used the LMS only for interactions with colleagues. Moreover, as soon as the teachers in schools with the family application started the process of technology implementation, they logged into the system approximately 1.5 more than teachers in schools connected only to their colleagues two years later - during the third year of implementation.

Table 3 shows results of the analysis of variance for the effect of the implementation time, use of family application, and the interaction between the two variables on the number of teacher logs into the system.

Table 3: The influence of implementation time, communication with families, and their interaction on the number of teacher logs into the system

\begin{tabular}{lcccc}
\hline \multicolumn{1}{c}{ Factor } & $\boldsymbol{F}$ & $\boldsymbol{d} \boldsymbol{f}$ & $\boldsymbol{p}$ & $\boldsymbol{\eta}^{2}$ \\
\hline Implementation time & 78.15 & 2,798 & $<.001$ & .09 \\
Communication with families & 78.02 & 1,799 & $<.001$ & .09 \\
Interaction & 8.57 & 2,798 & $<.05$ & .03 \\
\hline
\end{tabular}

As can be seen from the data, statistically significant main effects were found for the LMS implementation time, online communication with families through the system, as well as significant interaction between the two variables. Teachers in schools that used both staff and family applications logged significantly more into the system compared to teachers in schools that used the staff application only. Post-hoc test showed that the increase in teacher logs into the system continued in schools with the family application during all the period of investigation $\left(p^{\prime} \mathrm{s}<.001\right)$, while in schools without the family application significant increase occurred only from the first to second year of implementation $(p<.001)$, but not from the second to third year of technology adoption $(p>.98)$.

\section{Interactivity as the Percentage of the Daily Data Entered by Teachers into the System}

Regarding the first research hypothesis, the ANOVA Repeated Measures test showed a statistically significant effect of implementation time on the percentage of the daily data entered by teachers into the system, $F(2,498)=6.81, p<.001, \eta^{2}=.03$. Post-hoc tests showed significant increase only from the first to second year of LMS implementation (on average 74.12 and 78.95 
percents of daily data entered respectively, $p<.05$ ), but not from the second to third year of technology adoption (82.09 percent in average, $p<.17$ ).

Concerning the second research hypothesis, Table 4 shows comparisons between the number and percentage of teacher entering daily data versus the number of teachers logging into the system separately for teacher in schools with and without the Mashov family application.

Table 4: Comparison between the logging and data entering for teachers in schools with and without the Mashov family application

\begin{tabular}{lcc}
\hline Comparing logging and data entering & $\begin{array}{c}\text { Staff and family } \\
\text { applications }\end{array}$ & $\begin{array}{c}\text { Staff application } \\
\text { only }\end{array}$ \\
\hline Number of teacher logs & 660 & 141 \\
Number of teacher data entering & 454 & 46 \\
Percentage of teacher data entering & $68.8 \%$ & $32.6 \%$ \\
\hline
\end{tabular}

As can be seen, the percentage of teachers who actively interacted with their colleagues by entering data on a daily basis into the system was twice as high in schools that implemented both staff and family applications compared to teachers in schools that implemented staff application only.

Table 5 shows the average percentages and standard errors for the daily data entered by teachers into the system during the three years of LMS implementation, for teachers in schools implementing staff and family applications versus teachers in schools implementing staff LMS only.

Table 5: The percentage of the daily data entered by teachers into the system for schools with and without the Mashov family application

\begin{tabular}{lcc}
\hline $\begin{array}{c}\text { Period of daily data } \\
\text { entering }\end{array}$ & $\begin{array}{c}\text { Teachers implementing staff } \\
\text { and family applications } \\
(\boldsymbol{n}=\mathbf{4 5 4}): \text { Means }(\boldsymbol{S E})\end{array}$ & $\begin{array}{c}\text { Teachers implementing } \\
\text { staff application only } \\
(\boldsymbol{n}=\mathbf{4 6}): \text { Means }(\boldsymbol{S E})\end{array}$ \\
\hline First year & $75.76(1.17)$ & $57.85(3.64)$ \\
Second year & $79.70(2.35)$ & $71.46(4.39)$ \\
Third year & $83.20(2.37)$ & $71.08(4.45)$ \\
\hline
\end{tabular}

As can be seen from the table, although the staff was required to enter the data into the LMS on a daily basis and school principals could easily supervise if teachers carried it out, still teachers in schools implementing both the staff and family applications during the first year of usage entered a higher percentage of the daily data into the system compared to teachers in schools implementing the staff application only two year latter, during the third year of investigation.

Table 6 presents results of the analysis of variance for the effect of the implementation time, use of family application, and the interaction between these two variables on the percentage of data entered by teachers into the system on a daily basis.

Table 6: The influence of implementation time, communication with families, and their interaction on the percentage of daily data entered by teachers into the system

\begin{tabular}{lcccc}
\hline \multicolumn{1}{c}{ Factor } & $\boldsymbol{F}$ & $\boldsymbol{d} \boldsymbol{f}$ & $\boldsymbol{p}$ & $\boldsymbol{\eta}^{\mathbf{2}}$ \\
\hline Implementation time & 4.35 & 2,497 & $<.05$ & .03 \\
Communication with families & 6.18 & 1,498 & $<.01$ & .03 \\
Interaction & 0.83 & 2,497 & n.s. & .00 \\
\hline
\end{tabular}

As can be seen, statistically significant main effects were found for the time of implementation and for the communication with families using the Mashov LMS. Teachers in schools who com- 
Implementing Technological Change at Schools

municated online with students and their families through the Mashov family application entered significantly more daily data into the system compared to teachers in schools implementing the staff LMS only. The interaction between the period of implementation and communication with families was not statistically significant.

\section{Interactivity as the Number of Messages Sent by Teachers to Their Colleagues through the System}

Concerning the first research hypothesis, the ANOVA Repeated Measures test showed a statistically significant main effect of implementation time on the number of messages sent by teachers to their colleagues through the system, $F(2,580)=113.55, p<.001, \eta^{2}=.25$. Despite the pure voluntary nature of this activity and inability of school principals or colleagues to recognize the number of messages sent by other teachers, post-hoc tests showed significant increase in the average number of messages sent by teachers to their colleagues through the system during all three years of investigation $(30.63,73.35$, and 118.77 messages on average, $p$ 's $<.001)$.

Regarding the second research hypothesis, Table 7 shows comparisons between the numbers and percentages of teacher sending messages to their colleagues versus the number of teacher logging into the system, separately for teacher in schools with and without the Mashov family application.

Table 7: Comparison between the logging and message sending for teachers in schools with and without the Mashov family application

\begin{tabular}{lcc}
\hline Comparing logging and message sending & $\begin{array}{c}\text { Staff and family } \\
\text { applications }\end{array}$ & $\begin{array}{c}\text { Staff application } \\
\text { only }\end{array}$ \\
\hline Number of teacher logs & 660 & 141 \\
Number of teacher message sending & 509 & 73 \\
Percentage of teacher message sending & $77.1 \%$ & $51.8 \%$ \\
\hline
\end{tabular}

As can be seen, the percentage of teachers who actively interacted with their colleagues by sending messages through the system was significantly higher in schools implementing both staff and family applications compared to teachers in schools adapting the staff application only.

Table 8 presents means and standard errors for the number of messages sent by teachers to their colleagues through the system, separately for teachers in schools using both the staff and family applications versus teachers in schools implementing the staff application only.

Table 8: The number of messages sent by teachers to their colleagues through the system presented separately for schools with and without the Mashov family application

\begin{tabular}{lcc}
\hline $\begin{array}{c}\text { Number of messages } \\
\text { sent to colleagues } \\
\text { during: }\end{array}$ & $\begin{array}{c}\text { Teachers implementing staff } \\
\text { and family applications } \\
(\boldsymbol{n}=\mathbf{5 0 9}): \text { Means }(\boldsymbol{S E})\end{array}$ & $\begin{array}{c}\text { Teachers implementing } \\
\text { staff application only } \\
(\boldsymbol{n}=\mathbf{7 3}): \text { Means }(\boldsymbol{S E})\end{array}$ \\
\hline First year & $32.85(1.91)$ & $15.16(4.4)$ \\
Second year & $76.83(4.53)$ & $49.07(3.95)$ \\
Third year & $127.44(3.12)$ & $58.30(4.45)$ \\
\hline
\end{tabular}

As can be seen from the data, the number of messages sent by teachers to their colleagues in schools that used both staff and family applications was higher compared to teachers in schools that used the staff application only. 
Table 9 shows results of the analysis of variance for the effect of implementation time, use of family application, and the interaction between these two variables on the number of messages sent by teachers to their colleagues.

Table 9: The influence of implementation time, communication with families, and their interaction on the number of messages sent by teachers to their colleagues

\begin{tabular}{lcccc}
\hline \multicolumn{1}{c}{ Factor } & $\boldsymbol{F}$ & $\boldsymbol{d} \boldsymbol{f}$ & $\boldsymbol{p}$ & $\boldsymbol{\eta}^{\mathbf{2}}$ \\
\hline Implementation time & 30.78 & 2,579 & $<.001$ & .06 \\
Communication with families & 10.72 & 1,580 & $<.001$ & .04 \\
Interaction & 4.80 & 2,579 & $<.05$ & .03 \\
\hline
\end{tabular}

As can be seen from the data presented, statistically significant main effects were found for the LMS implementation time, online communication with families through the Mashov system, as well as a significant interaction between the two variables. Teachers in schools that used both staff and family applications sent significantly more messages to their colleagues through the system compared to teacher in schools that used the staff application only. Post-hoc test showed that in schools without family applications significant increase in the number of messages sent by teachers to their colleagues occurred only from the first to second year $(p<.001)$, but not from the second to third year of implementation $(p>.58)$, while in schools in schools with family application the increase in the number of messages sent by teachers to their colleagues continued during all the period of investigation $(p ' s<.001)$.

\section{Discussion}

The purpose of this study was to examine different forms of online interactions among teachers during implementation of new technology - Mashov LMS - in Israeli secondary schools, in order to contribute to the conceptual understanding of implementing technological change in educational institutions. (1) Based on the Diffusion of Innovation Theory (Rogers, 2003), it was hypothesized that the implementation time would positively influence all three measures of the interactivity (i.e., logging into the system, reporting data on a daily basis, and sending messages to colleagues). (2) Based on the approach of implementing changes at schools by expanding the circles of interaction and integrating all stakeholders (Fuchs, 1995), it was hypothesized that opening the possibility for online interactions with students and their parents would augment all three measures of interactivity among the teachers themselves. Both hypotheses were supported for all three measures of interactivity.

Concerning the interactivity measured as teachers logging into the system, consistent with the first research hypothesis and the Diffusion of Innovation Theory (Rogers, 2003), the findings showed that implementation time influenced the number of teacher logs into the system that increased during all three years of investigation. According to the second hypothesis, teachers who interacted online with students and their parents logged more into the system compared to teachers in schools using the LMS only for the staff interactions. Moreover, the increase in teacher logs into the system continued in schools using the family application during all the period of investigation, while in schools without family application the increase in teacher logs stopped after the second year of implementation. The results are consistent with Fuchs's (1995) framework and Bowyer, Gerard, and Marx's (2008) findings that conclude the role of stakeholders in incorporating technology within organizational everyday practices is an important step towards the effective and successful implementation of technology. This result is especially interesting taking into consideration that teachers in schools implementing the LMS for staff only were on average younger compared to teachers in schools using both the staff and family applications. It seems that consistent with Rogers's (2003) general claim concerning irrelevance of the age to technology adoption, 
the teacher age was irrelevant for successful adoption of LMS technology in educational institutions.

Regarding the interactivity as the percentage of daily data entered by teachers, consistent with the first research hypothesis, implementation time influenced the percentage of daily data entered by teachers into the system. However, the increase in the percentage of the daily data was found only from the first to second year of LMS implementation. Entering data on a daily basis is a required action; it seems that its implementation was influenced by transparency of the action and easy supervision by school principals. The adoption of technology in the organizational settings may add new variables influencing on participant online behavior that are not covered by the more generic Diffusion of Innovation Theory (Rogers, 2003). According to the second research hypothesis, although the staff was required to enter the data into the LMS on a daily basis and school principals could easily supervise if teachers carried it out, teachers in schools communicating online with students and their families through the system entered significantly more daily data compared to teachers in schools implementing the staff LMS only. This finding is consistent with the approach of implementing changes in schools by expanding circles of interaction (Fuchs, 1995) and including all stakeholders into the adoption process (Bowyer et al., 2008). It seems that, in addition to the external motivation based on the supervision by school principal, the transparency of the data to real target audience - students and families - gives additional internal stimuli for teachers to enter data into the system on a regular basis.

Concerning the interactivity as the number of messages sent by teachers to their colleagues through the system, according to the first research hypothesis, implementation time affected the number of messages sent by teachers to their colleagues. Despite the pure voluntary nature of this activity and inability of school principals or colleagues to recognize the amount of correspondence sent by other teachers, findings showed an increase in the number of messages sent by teachers to their colleagues through the system during all three years of investigation. This finding is consist with the Diffusion of Innovation Theory (Rogers, 2003), as well as with the data presented by Peled, Kali, and Dori (2007). According to the second hypothesis, teachers in schools that used both staff and family applications sent significantly more messages to their colleagues through the system compared to teacher in schools that used the staff application only. Moreover, in schools without family application, the significant increase in the number of messages sent by teachers to their colleagues stopped after the second year of implementation, while in schools with family application the increase in the number of messages sent by teachers to their colleagues continued during all the period of investigation. This finding is consistent with the theoretical approach (Fuchs, 1995) and empirical findings (Bowyer et al., 2008) of previous studies regarding the importance of interactions with stakeholders, such as students and their parents, during the implementation of change. Because this activity is voluntary, non-transparent to school principal and colleagues, and does not affect student performance, the number of messages sent by teachers to their colleagues serves as a "pure" measure of interactivity derived mostly from internal motivational sources. It seems that teachers in schools implementing both staff and family applications have more issues to discuss online with their colleagues through the system compared to teachers in schools using the staff application only.

A further aim of this paper was to provide some insights of the decisions behind good practices that may contribute to the discussion and reflection on technology use in educational settings. The results of the study showed that schools successfully assimilated the Mashov LMS into their school-culture. We refer to the term "assimilation of LMS use into school culture" in order to describe the situation showed by the results of this study, in which, aligning with the school's vision, almost all teachers are frequently logging into the system, entering data regarding their lessons, student performance and behavior events, and maintaining online communication with their colleagues. 
Fishman, Marx, Blumenfeld, Krajcik, and Soloway (2004) suggested that effective implementation of technology in educational settings requires teachers and principals to embrace technology into the school culture and revisit the school's vision. This re-thinking process and reshaping a school's vision for incorporating technology are important regarding the success of the implementation process (Bowyer et al., 2008). Previous research showed (Peled et al., 2007) that school principals play a key role in this process. Peled et al.'s study showed that principals who convey the message that technology serves as an integral part of the school practices and supports teachers in the implementation process, both in a personal manner and organizational levels, motivate teachers to take growing responsibilities related to technology incorporation into their everyday practices. It seems that the Mashov LMS meets the organizational requirements of school principals by instantly conveying all school pedagogical information and giving the possibility to easily extract this information from different perspectives and in different levels (e.g., data of individual student, groups, classes, whole school, subject-matter, teacher, team, etc.). These features lead to the strong support of school principals for implementing the LMS in their institution. In addition to the external push, teachers quickly learn to extract information about their classes, subjectmatter groups, etc., and use this information for their own educational benefits. Research showed that in order to achieve long-term technology adaption in schools, bottom-up and top-down processes should be combined (Shamir-Inbal et al., 2009). This combination of external support and understanding of internal benefits for teacher leads to the successful implementation of Mashov LMS in the personal and organizational levels. Teachers play a key role in establishing the change and implementing the technology, while technological support is provided by the Mashov design team, and the endorsement and support are provided by school authorities.

\section{Conclusion}

This study examined online interactions among teachers during implementation of new technology - Mashov LMS - in Israeli secondary schools. Both study hypotheses were supported. (1) Consistent with the Diffusion of Innovation Theory (Rogers, 2003), findings showed that implementation time positively influenced all three measures of interactivity (i.e., logging into the system, reporting data on a daily basis, and sending messages to colleagues). However, for transparent and supervised type of interactivity - reporting data in a daily basis - the process of adoption ended after the second year, while for two other types of interactivity the increase in use continued during all the period investigated in this study. This difference suggests that the adoption of technology in organizational settings may be influenced by additional variables not covered by the generic Diffusion of Innovation Theory. (2) Consistent with the approach of implementing changes in schools by expanding circles of interaction and including all stakeholders (Fuchs, 1995), it was found that the possibility for online interactions with students and their parents augments all three forms of the interactivity among teachers measured in this study. It seems that teachers in schools implementing both staff and family applications have more reasons to log into the systems, more motivation to exchange pedagogical information on a daily basis through the system, and more issues to discuss online with their colleagues compared to teachers in schools using only the staff application. Therefore, we recommend to schools administrators and LMS designers to take into consideration the importance of educational institution stakeholders - students and their families - partaking in the implementation of the technological change. 


\section{References}

Black, E. W., Dawson, K., \& Priem, J. (2008). Data for free: Using LMS activity logs to measure community in online courses. Internet and Higher Education, 11, 65-70.

Blau, I., \& Hameirie, M. (2010). Implementing technological change: Promoting online interactions at schools through "Mashov" Learning Management System. In Y. Eshet-Alkalai, A. Caspi, S. Eden, N. Geri, \& Y. Yair (Eds.), Learning in the technological era (pp. 24-31). Ra'anana, Israel: Open University of Israel [in Hebrew].

Bowyer, J., Gerard, L., \& Marx, R. (2008). Building leadership for scaling science curriculum reform. In Y. Kali, M. C. Linn, \& J. E. Roseman (Eds.), Designing coherent science education: Implications for curriculum, instruction, and policy (pp. 123-152). New York: Teachers College Press.

Cameron, L., \& Mahoney, K. (2008). Introducing a Learning Management System (LMS) into your school: Some considerations. In Proceedings of World Conference on Educational Multimedia, Hypermedia and Telecommunications 2008 (pp. 2826-2831). Chesapeake, VA: AACE.

Chen, L., \& Epperson, C. (2008). Enhancing limited English proficiency (LEP) students' learning with a Learning Management System (LMS). In G. Richards (Ed.), Proceedings of World Conference on ELearning in Corporate, Government, Healthcare, and Higher Education 2008 (pp. 3634-3638). Chesapeake, VA: AACE.

Cho, C-H., \& Leckenby, J. D. (1999). Interactivity as a measure of advertising effectiveness. In M. S. Roberts (Ed.), Proceedings of the American Academy of Advertising (pp. 162-179). Gainesville, FL: University of Florida.

Dori, Y. J., Tal, T., \& Peled, Y. (2002). Characteristics of science teachers who incorporate web-based teaching. Research in Science Education, 32, 511-547.

Drucker, P. F. (2007). The practice of management (Revised ed.). New York: Harper Business.

Fishman, B., Marx, R., Blumenfeld, P., Krajcik, J. S., \& Soloway, E. (2004). Creating a framework for research on systemic technology innovations. Journal of the Learning Sciences, 13, $43-76$.

Fuchs, I. (1995). Change - A way of life in schools. Tel-Aviv: Cherikover publishers [in Hebrew].

Georgouli, K., Skalkidis, I., \& Guerreiro, P. (2008). A framework for adopting LMS to introduce e-learning in a traditional course. Educational Technology \& Society, 11, 227-240.

Greenberg, L. (2002). LMS and LCMS: What's the difference? Retrieved March 3, 2010 from http://niubt.360doc.com/content/080419/22/9601_1201270.html

Heathcote, E., \& Dawson, S. (2005). Data mining for evaluation, benchmarking and reflective practice in a LMS. Paper presented at the E-Learn 2005: World Conference on e-Learning in Corporate, Government, Healthcare, \& Higher Education. Vancouver, Canada.

Maleh, N. A., Lee, C. S., Ho, C. K., \& Chong, H. R. (2004). Conceptual framework for enhancing the instructional design process. Malaysian Online Journal of Instructional Technology, 1, 1-5. Retrieved March 3, 2010 from http://pppij.usm.my/mojit/articles/V1N2-final/MOJIT-013-Norliana.htm

Nichani, M. (2001). $L C M S=L M S+C M S$ [RLOs]. Retrieved March 3, 2010 from http://www.elearningpost.com/features/archives/001022.asp

Peled, Y., Kali, Y., \& Dori, Y. J. (2007). Interaction between science teachers and school principals and its influence on technology implementation: A retrospective analysis. In Y. Eshet, A. Caspi, \& Y. Yair (Eds.), Learning in the technological era (pp. 117-121). Ra'anana: Open University of Israel.

Rafaeli, S., \& Ariel, Y. (2007). Assessing interactivity in computer-mediated research. In A. N. Joinson, K. Y. A. McKenna, T. Postmes, \& U. D. Rieps (Eds.), The Oxford handbook of internet psychology (pp. 71-88). Oxford: Oxford University Press.

Rengarajan, R. (2001). LCMS and LMS - Taking advantage of tight integration. Retrieved March 3, 2010 from http://www.e-learn.cz/soubory/lcms and lms.pdf 
Rogers, E. M. (2003). Diffusion of innovations (5th ed.). New York: Free Press.

Sundar, S. S., \& Kim, J. (2004). Interactivity and persuasion: Influencing attitudes with information and involvement. Paper presented at the Communication and Technology division at the 54th annual Conference of the International Communication Association. New Orleans, LA.

Samsup, J., \& Yungwook, K. (2003). The effect of web characteristics on relationship building. Journal of Public Relations Research, 15, 199-223.

Shamir-Inbal, T., Dayan, J., \& Kali, Y. (2009). Assimilating online technologies into school culture. Interdisciplinary Journal of E-Learning and Learning Objects, 5, 307-334. Retrieved from http://www.ijello.org/Volume5/IJELLOv5p307-334Samir-Inbal675.pdf

Steel, C. (2009). Reconciling university teacher beliefs to create learning designs for LMS environments. Australasian Journal of Educational Technology, 25, 399-420.

Tsai, Y-R., \& Ernst, C. A. (2009). The model and implementation of a Course-Management-System (CMS)-assisted EFL reading strategy instruction. International Journal of Digital Learning Technology, 1, 203-223.

\section{Biographies}

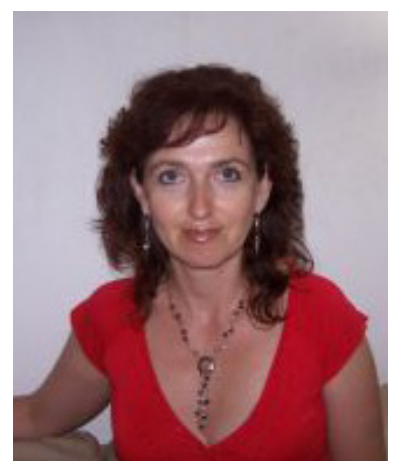

Dr. Ina Blau holds a PhD in E-Learning and CyberPsychology from the University of Haifa. She is a faculty member in the Department of Education and Psychology at the Open University of Israel and in the Department of Education at the Western Galilee College. She is also a member of Chais Research Center for the Integration of Technology in Education. Her research interests include social aspects of Internet use and e-communication, online participation patterns, and integration of innovative technologies in teaching and learning.

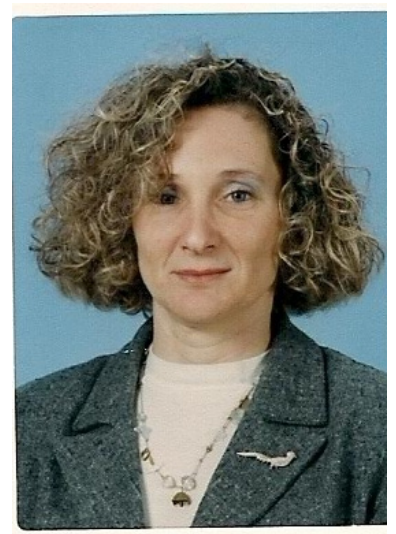

Dr. Mira Hameiri holds a PhD in Technology \& Science Education from the Technion - Israeli Institute of Technology. She is a Director of the Center for Professional Development of School Principals \& Inspectors in Oranim Academic College of Education, Israel. Her research interests focus on leadership and integration of technology in education. 